\title{
LETTERS
}

\section{Improved cell-purification techniques and safety monitoring needed for olfactory ensheathing cell transplantation}

Woodworth and colleagues highlight an important complication 12 years after a patient received a transplantation of olfactory mucosa tissue into the spinal cord. This report, combined with others cited by the authors, emphasizes that long-term follow-up after cell transplantation must be performed and reported as a matter of routine. This is essential for ensuring adequate patient safety; yet, it is at odds with the short follow-up times specified by many current trials on cell therapy.

We find it unsurprising that aberrant growth was observed after the transplantation of whole olfactory mucosa tissue. The olfactory mucosa is rich in a number of cell types, ${ }^{2}$ including the pseudostratified columnar epithelial cells noted on histology from the patient in this case. ${ }^{1}$ In the original study by Lima and colleagues, the use of whole tissue was justified because cell suspensions lead to poor cell viability and do not adequately fill the lesion space. ${ }^{3}$ These concerns are justifiable, ${ }^{4}$ but we challenge the idea that transplanting whole tissue is the only way to overcome such issues. Indeed, we would like to draw attention to new approaches being developed by our group and others, ${ }^{5}$ in which tissue engineering and biomaterial-based approaches have the potential to enhance the delivery of olfactory ensheathing cells.

Olfactory ensheathing cells still have great potential for treating spinal cord injuries, ${ }^{6}$ but this case report in $C M A J^{1}$ reinforces the need for improved cell-purification techniques and safety monitoring. A better understanding of the constituents of the source material and the potential beneficial or adverse effects of individual cell subgroups within the mucosa would be desirable before further clinical studies take place.

\section{Richard D. Bartlett iBsC}

$\mathrm{MB} / \mathrm{PhD}$ researcher, University College London Centre for Nerve Engineering, London, UK

\section{James B. Phillips PhD}

Reader in regenerative medicine, University College London Centre for Nerve Engineering, London, UK

\section{David Choi MBChB PhD}

Professor of neurosurgery, University

College London Centre for Nerve

Engineering and National Hospital for

Neurology and Neurosurgery, London, UK

Cite as: CMAJ 2019 October 28;191:

E1199. doi: 10.1503/cmaj.73255

\section{References}

1. Woodworth CF, Jenkins G, Barron J, et al. Intramedullary cervical spinal mass after stem cell transplantation using an olfactory mucosal cell autograft. CMAJ 2019;191:E761-4.
2. Chen CR, Kachramanoglou C, Li D, et al. Anatomy and cellular constituents of the human olfactory mucosa: a review. J Neurol Surg B Skull Base 2014; 75:293-300.

3. Lima C, Pratas-Vital J, Escada P, et al. Olfactory mucosa autografts in human spinal cord injury: a pilot clinical study. J Spinal Cord Med 2006;29: 191-203, discussion 204-6.

4. Li Y, HI Yu, Chen LF, et al. Survival and number of olfactory ensheathing cells transplanted in contused spinal cord of rats. Chin J Traumatol 2010;13: 356-61.

5. Bartlett R, Roberton V, Choi D, et al. Tissue engineering to enhance cell therapy for traumatic spinal cord injury. In Proceedings of the Twelfth International Conference on Tissue Engineering \& Regenerative Medicine; 2019 Nov. 11-12 2019; Madrid (Spain);p. 740.

6. Watzlawick R, Rind J, Sena ES, et al. Olfactory ensheathing cell transplantation in experimental spinal cord injury: effect size and reporting bias of 62 experimental treatments: a systematic review and meta-analysis. PLoS Biol 2016;14:e1002468.

Competing interests: Richard Bartlett reports grants from The Sackler Fund (MB/PhD award). James Phillips is the co-founder of the University College London (UCL) spin-out company Glialign Ltd., which focuses on peripheral nerve repair (not spinal cord injury, which is the subject of this letter). He has received no income from the company and is not a director. James Phillips is an inventor on the following patents: 2013 Phillips and Georgiou, Engineered neural tissue (WO 2015015185); and 2004 Phillips and Brown, Self-aligning tissue growth guide (wO 2004087231). These are broadly in the area of organizing therapeutic cells within hydrogels but are not linked to any of the studies reported in the manuscript. David Choi reports support from University College London Hospitals National Institute for Health Research Biomedical Research Centre and grants from Wellcome Trust. 